\title{
Formas urbanas de religiosidad Popular. El caso Cromañón en Buenos Aires
}

\section{Maximiliano Korstanje}

Magíster (c) en Sociología, Universidad Católica Argentina Licenciado en Turismo, Universidad de Morón.

Asesor técnico de CEO de la firma Hertz Argentina.

maxikorstanje@hotmail.com

Resumen

El objetivo del presente artículo es determinar si existe un fenómeno de religiosidad popular, por las consecuencias sociales del caso del incendio provocado por una bengala en un recital de un grupo de rock en Buenos Aires. Se analiza que se entiende por religiosidad popular y se toman cinco elementos: la sacralización de los muertos, la idea de conflicto social, el sincretismo, las fechas conmemorativas, y la promesa como relación entre el devoto y el santo. Finalmente, mediante entrevistas en profundidad, observación participante y no participante se establece una relación entre esas categorías teóricas y los hechos empíricos.

\section{Abstract}

The objective of the present article is to determine if a phenomenon of popular religiosity it does exists, by the social consequences of the case of the fire caused by a flare in a recital of a rock band in Buenos Aires city. It is analyzed what it is understood by popular religiosity and five elements are taken: the sacralization of the deads, the idea of social conflict, the syncretism, the commemorative dates, and the promise like relation between devotee and the saint. Finally, by means of interviews in depth, participant and non-participant observation settles down a relation between those theoretical categories and the empirical facts.

\section{Palabras Clave: Religiosidad popular/ Sincretismo/ Conflicto social/ Rituales/ Devoción}

\section{Introducción}

El día 30 de Diciembre de 2004 se desataba un incendio provocado por una bengala en un recital que el grupo de rock "Callejeros" llevaba a cabo en el local La República de Cromañón, ubicado en el barrio porteño de Once frente a la plaza Miserere; en este hecho morían trágicamente 194 personas.

Como consecuencia, Omar Chaban el dueño del local donde se desarrolló el siniestro fue procesado y privado de su libertad, los integrantes del grupo "Callejeros" fueron procesados y en Marzo de 2006, el entonces intendente porteño Dr. Aníbal Ibarra era destituido tras un juicio político sin precedentes iniciado por la legislatura.

Pasados dos años de esta tragedia, se encuentra hoy un espacio en homenaje a esas víctimas, donde sus familiares y amigos tienen la oportunidad de expresar sus sentimientos más profundos. ¿Es Cromañón un símbolo de religiosidad popular?, 
¿Qué particularidades presenta y cuáles son sus ritos más característicos?, ¿Qué elementos dan origen a esta expresión?

\section{¿Qué es la religiosidad popular?}

Definir que se entiende por religiosidad popular es una tarea difícil. A lo largo de la historia, tanto la teología, como la sociología y la antropología se han dedicado al tema. Sin embargo, en la actualidad no existe una definición clara y consensuada de religiosidad popular. (Martín, 2003:6) (Frigerio, 2000)

Pablo Seman (2001) afirma que en toda religiosidad popular existen claramente definidos tres elementos constitutivos: una variable cosmológica y holista por un lado y un carácter relacional por el otro.

Para Floreal Forni (1986) fue la migración europea la que trajo consigo las primeras prácticas de religiosidad popular. "el caso de la Argentina litoral, Montevideo y quizá San Pablo son excepcionales y sumamente interesantes al mismo tiempo. Estas áreas urbanas recibieron emigrantes europeos a principio de siglo que trajeron consigo patrones de religiosidad popular y también una fuerte tradición anticlerical (de origen socialista y anarquista) ajena a la población nativa" (Pág. 12) Pero esta clase de religiosidad era diferente, y tenía consigo caracteres muy distintivos, "una contribución germánica basada en la devoción una imagen especial, Patrono o Santo especializado, uno por cada actividad, problema o elección personal; y un culto de los muertos. Este estilo de catolicismo, que Weber en los comienzos del siglo veinte localizaba en el sur de Europa, es probablemente el más ampliamente difundido entre las clases populares en Latinoamérica" (Pág. 17).

Por ese motivo, lo primero que debe establecer el investigador es un concepto flexible al caso que está investigando. A nuestro entender el ejemplo más claro para una definición del tema es la que trabaja el español Manuel Delgado. Para el autor, la lectura de los trabajos sobre religiosidad popular no han sino evidenciado su insuficiencia explicativa ante presencias o prácticas que no habían sido contempladas anteriormente.

Algunas veces, considerando a las manifestaciones populares como una especie de secta, otras dándole un carácter contrapuesto a la estructura religiosa oficial. De esa manera la religiosidad popular se encuentra muchas veces legitimada por la religión oficial y es producto de sus mensajes. (Delgado, 1993: 11)

En muchas ocasiones, es el pueblo el que canoniza a los santos populares, usando una denominación propia de la Iglesia Católica pero ajena a su reconocimiento. ( Carozzi, 2005: 1)

Usando la definición de Soneira (1986: 187), nosotros entendemos como religiosidad popular, a toda práctica, acto, conducta o sentimiento masivo que funciona como estructura mediadora entre la matriz sagrada y los grupos humanos en forma paralela en algunos casos o enfrentada en otros, a las prácticas del sistema religioso oficial. Si bien la naturaleza de los elementos que hacen a esta religiosidad difieren con respecto a cada contexto social, existen cinco de ellos que son comunes a todas estas prácticas: la sacralización de los muertos, la idea de conflicto o lucha social de las clases menos privilegiadas, el sincretismo, ciertas fechas de conmemoración bien 
definidas, y la promesa como elemento relacional entre lo sagrado y el grupo humano.

Aquí surgen dos preguntas por demás interesantes, ¿qué puede decirse de cada uno de estos elementos por separado?, y ¿cómo se vinculan con la tragedia de Cromañón?

\section{La Sacralización de los muertos}

El historiador francés del sigo XIX, Fustel de Coulanges había descubierto una relación entre el culto a los muertos y la génesis de las primeras manifestaciones religiosas en griegos y romanos, a los que él denominaba "los antiguos". Mediante un erudito estudio histórico, el autor sostiene la tesis de que las religiones indo-europeas tienen su origen en el culto a los muertos. En efecto, en la antigüedad cada familia tenía un dios lar protector que no era otro que la memoria de sus familiares fallecidos; alrededor del hogar existía un fuego sagrado el cual el padre de la familia debía alimentar con ofrendas; una vez extinguido el fuego se disolvía la familia. (Coulanges, 2005)

Según los comentarios de uno de nuestros informantes claves (Marcelo) ${ }^{1}$, "el santuario" de Cromañón se puso en marcha el primero de enero de 2005, apenas se habían sucedido dos días de la tragedia. Al principio, sólo estaban en pie los canteros con una cruz y decorado a su alrededor con rosarios y zapatillas que pertenecían a los fallecidos. Luego, la gente se fue acercando y dejando ofrendas a sus seres queridos. Así poco a poco se fue formando lo que hoy teníamos ambos frente a nuestros ojos. Por algún motivo, que él desconoce, "el santuario" fue destruido pero la tenacidad de los amigos y los familiares nuevamente volvió a reconstruirlo en cuestión de días.

Visualmente, el lugar puede dividirse en tres: una zona a la izquierda en la cual están ubicadas unas sillas, fotos de las víctimas y muchas zapatillas acordonadas una al lado de la otra. La misma, rememora el lugar donde se apilaron los primeros cadáveres y actualmente corta la calle Bartolomé Mitre en dos.

En el centro, se encuentra la entrada principal al santuario en donde puede verse un cartel con la leyenda "En memoria de los 194 ángeles masacrados en Cromañón, seguimos pidiendo justicia y verdad para que descansen en la paz que se merecen". Este lugar, tiene lápidas con un aspecto muy similar a un cementerio, aún cuando los cuerpos no se encuentran enterrados allí.

Luego a la derecha, un mural con los nombres de las víctimas y una leyenda "los pibes de Cromañón presentes, ahora y siempre". Esta última leyenda, se instituyó con la muerte del periodista José Luís Cabezas, y hasta el momento es enarbolada por todos los familiares y amigos de quienes fallecen en circunstancias violentas.

En las lápidas, se pudo observar la foto de un joven de apellido Benítez juntando sus manos en forma de rezo. Otra foto de una adolescente que dice "sos nuestro angelito". La idea de que las víctimas se transformaron seres sagrados como ángeles o astros, como "estrellas o soles" es recurrente en este lugar.

Aquí, la interpretación tiene otro significado y corresponde a la sacralización o idealización de los muertos. Pero estos seres son en cierta forma especiales y desde 
su mundo nos brindan protección y seguridad. Se han recopilado extractos de cartas y mensajes que prueban lo afirmado tales como los que a continuación se detallan:

- "el cielo ganó un ejercito de ángeles pero quedaron cientos de hogares vacíos". (Carta anónima).

- "Maty desde el cielo me miran tus ojos a donde voy"

- "fuiste un ser lleno de bondad y compasión te amamos más allá de toda razón".

- "que descansen en paz ángeles del cielo, que este recital terminará en cualquier momento"

- "Sos el ángel que nos da fuerza para seguir viviendo, yo se que de algún lado vos nos estás ayudando".

El siguiente fragmento corresponde a un poema dedicado a uno de los fallecidos:

"No llores si me amas

Si conocieras el Don de Dios

Y lo que es el cielo

Si pudieras oír

El cántico de los Ángeles

Y verme en medio de ellos

Si por un instante pudieras

contemplar como yo

La belleza ante la cual

Las bellezas palidecen ...".

También hay mensajes y poemas haciendo referencia a ciertos astros:

Un extracto de un poema dedicado a Marcelo Lameza dice

"Sos la estrella que titila

y palpita incandescentemente

en el alma y en la mente

De los que te amamos siempre

Sos la estrella que ilumina

Los recuerdos más bonitos

Que construistes contento

Con tus seres más queridos"

Carta anónima: Por la noche, mirarás las estrellas, cuando mires el cielo, como yo habitaré en una de ellas, como yo reiré en una de ellas, será para ti como si vieras todas las estrellas"

En conmemoración del hecho, a un año de sucedido, el diario Clarín titulaba un artículo "Buenos Aires tiene que llorar y ser purificada por las lágrimas". La Catedral de Buenos Aires había sido el epicentro de un acto conmemorativo por Cromañón. El párrafo final del artículo señalaba "a la salida, quienes asistieron a la misa encontraron un panorama distinto al de la entrada: la plaza estaba llena, lista para acompañar a los familiares en su marcha hasta el boliche de Once, el lugar que enlutó sus vidas hace ya un año, el santuario que insistirá hoy y siempre en defender su memoria". (Elustuondo, 2005) Dos elementos son distintivos en este artículo la 
idea de purificación mediante el sacrificio, la memoria a través del santuario como recordatorio de ese sacrificio.

Una carta a una de las víctimas titulada "gracias por dejar el alma" evidencia la relación que existe entre el siniestro, la noción de lo sagrado y el conflicto social como característico del santuario. Otra de las dedicatorias dice así “Te despediste con mucha alegría y te marchaste con rumbo al cielo, después de tantos golpes, tantas alegrías, tanto sufrimiento entre familia. Hoy nos haces mucha falta pero sabemos que desde tu mundo que es el cielo tu lugar, nos miras y sonreís como siempre estuviste con tus seres queridos".

La muerte de los 194 jóvenes es orientada hacia un fin el cual los transforma en mártires. No han muerto en vano, su muerte ha servido a un propósito más elevado lo cual los transforma en mediadores ante Dios. Por ejemplo, uno de los carteles ubicados al lado de la imagen de Jesús y María decía claramente "Si no existe memoria todo lo nuestro es Suicida. JUSTICIA!" Otro de los carteles decía "Romina Castro... Tu vida se llevó un poquito de las nuestras, y nos dejó el tesoro de tu inocencia, esperamos que tu alma se pueda perdonar a los que apagaron tu llamita y las de muchos otros"

La historia nos dice, que en las prácticas religiosas de los judíos en la antigüedad, el sumo pontífice vestido con una túnica blanca celebraba junto a sus fieles "el día de la expiación", el cual simbolizaba la purificación de las culpas por medio de un sacrificio, de esa forma sacrificando un animal sagrado el pueblo era absuelto de todos sus pecados y abominaciones. El chivo expiatorio, era el macho cabrío que servía a tal fin. Esa tradición judeo-cristiana, se conserva hasta nuestros días; por ejemplo cuando culpamos de las acciones colectivas a determinados personajes que absorben toda la responsabilidad.

He aquí otro de los elementos que hacen a la religiosidad popular, el conflicto social ante una autoridad que por diversos motivos es seriamente cuestionada.

\section{El conflicto social}

La necesidad de lo sagrado, se encuentra expresada a través de la magia o la religión, para hacer frente a un poder opresor, autoritario, siniestro, corrupto etc. Pero ese enfrentamiento no es la causa última, sino la necesidad de un nuevo orden.

El "santuario" parece ser una forma de orden ante la presencia del caos; un caos que se deriva de la incertidumbre, el dolor y la tensión acaecida tras un hecho que nos señala que cualquiera podría haber sido la víctima. De ello se desprende la necesidad de reiterar en cuanto discurso se observa que lo acontecido en Once aquel fatídico 30 de Diciembre se podría haber evitado y la necesidad de controlar un azar doloroso a través del sacrificio "a los dioses" de un "chivo expiatorio".

El periodista Marcelo Moreno de Clarín afirma "es posible, lo más probable que todo se deba al abismo tan profundo, tan sin fondo del dolor con su poder de hacernos cambiar y hasta de extraviar la naturaleza de las cosas... a eso quizás se deba la urgencia perentoria, reiterada, casi compulsiva de encontrar culpables absolutos en una desgracia. Una desgracia que asombra que no se reitere". (2005: 16) 
En la observación de campo, hemos podido notar diversas leyendas sino la mayoría de ellas pidiendo justicia. El objeto hacia el que se orienta la hostilidad es el poder político encarnado en el ex intendente Dr. Aníbal Ibarra y el económico en Omar Chaban. Muchos de los mensajes estaban orientados en esta dirección:

"porque se siga con los ojos abiertos, no sólo viendo sino haciendo, porque toda lucha siga viva".

"Ibarra y Chaban culpables por la masacre de Cromañón"

"Luchemos porque la justicia contra la impunidad y la corrupción".

"Razón y Revolución".

"no bajen los brazos"

" a los que el cielo no pudo esperar, no olvidar siempre resistir".

Sin embargo, el más representativo es una pegatina con una cruz negra y en el centro la cara de Ibarra con la leyenda "I barra candidato asesino 2007-2011".

En la actualidad, existen sitios en la Web que se dedican al igual que el santuario mantener viva la memoria". Tales son los casos de www.Cromañón.com.ar o www.quenoserepita.com.ar, bajo el lema "atención!, no los mató el incendio los mató la corrupción" o "si toleras Cromañón el próximo podes ser vos o tu hijo".

Dentro de lo que representa Cromañón, el discurso toma elementos de otros hechos trágicos sucedidos en la historia argentina y alimenta así su fuego interno. Es común ver en esta clase de fenómenos alusiones y reivindicaciones de casos no esclarecidos en donde aparecen seriamente involucrados sectores poderosos e influyentes. Aunque diferentes, quizá en su naturaleza estos hechos se van mimetizando y alimentan su discurso recíprocamente. No es extraño observar por ejemplo a los padres de Natalia Melman en actos públicos organizados por los familiares de las víctimas de Cromañón. Como así tampoco encontrar alusiones a los atentados trágicos contra la comunidad judía o el asesinato del reportero gráfico José Luís Cabezas.

Entre los padres, seguidores del grupo y sobrevivientes las posiciones son totalmente encontradas. Un grupo sigue fielmente a la banda y acusa de lo sucedido a Ibarra, otro deslinda a Chaban y acusan al Grupo e Ibarra, otros apuntan su odio hacia Chaban e Ibarra y también están aquellos que apuntan directamente sobre el grupo Callejeros.

Entre los grupos más conocidos, que se formaron tenemos a: Que no se repita, Justicia por la masacre de Cromañón, Justicia por los Pibes, Cambiar esta Realidad, y los pibes de Cromañón entre otros. Pero existen otros muchos tales como APHAC (Asociación de Padres e Hijos asesinados en Cromañón), quienes a través de diferentes reuniones van articulando su plan de lucha.

De todos modos, no todos aquellos que asisten al "santuario" encarnan algún tipo de lucha o persiguen un objetivo: la mitad o un poco más de ellas son visitantes que son atraídos por el lugar, o como lo señala Marcelo "ven que hay un montón de cosas llamativas y se acercan a ver que pasa". En muchos casos cuando uno se acerca a ellos y les pregunta que piensan de lo sucedido en Cromañón responden "yo sólo vine a ver que había aquí, estoy paseando". 


\section{El Sincretismo}

Se hace uso de este término cuando se estudia el surgimiento de nuevas formas de religiosidad. El concepto encierra una idea de fusión, mezcla de prácticas religiosas en forma independiente de la matriz sagrada. Uno de los casos más representativos de sincretismo, es la presencia de rituales y símbolos pertenecientes a religiones afrobrasileñas en ritos católicos. Soneira (1986: 256) advierte que muchas de las prácticas religiosas que se observan hoy en Brasil son provenientes de etnias como los Yoruba, los Ewe o los Bantú traídas con la esclavitud hoy presentes en la santería, el vudú, el Xang, y Shango entre otros. Obviamente, estas prácticas se fusionaron en forma sintética con algunas de las católicas dando origen al Umbanda (Brasil), Culto a María Lionza (Venezuela) y Catimb (al norte de Brasil).

En nuestro caso de estudio, existen ejemplos bien claros de sincretismo cuando se observan en el mismo lugar, banderas de grupos de rock con leyendas con apoyo al grupo Callejeros, insignias de cuadros de fútbol el cual era seguidor la víctima, y en accesorios a la vestimenta como las muchas zapatillas atadas que se encuentran ubicadas en la parte izquierda del santuario junto a símbolos propios de la religión católica tales como la imagen de la virgen, santos tales como San José, San Expedito, San Esteban o San Pío de Pietrelina, cruces, rosarios, velas o menciones a los ángeles como figuras sagradas entre otros.

Por ejemplo, en el fondo de la parte central del santuario hay una imagen de la Virgen María sosteniendo el cuerpo de Jesús recién bajado de la cruz, justo al lado una mesa que parece ser destinada para celebrar misas.

María Julia Carozzi (2003b: 66) había observado en los cultos de religiosidad popular como el de Carlos Gardel en el Cementerio del Oeste la relación que existe entre el santo y su club de fútbol preferido en vida. En este caso se habían dejado frente a su tumba escudos de Racing Club de Avellaneda, con el cual simpatizaba Gardel. ${ }^{3}$

Según dos entrevistados, las zapatillas de tela tipo "Topper" tan evidentes desde lo visual, simbolizan que el "Rock está presente en el santuario y que en cierta forma los pibes murieron tocando o escuchando rock". En una de las leyendas, se observa "Korneta no se murió está tocando con Papo". Recordando al también difunto ídolo del rock Nacional Norberto Napolitano, alias Papo, quien perdiera la vida trágicamente en un accidente de tránsito con Korneta Suarez ex líder de los Gardelitos.

Al igual que otros ídolos de la música como Rodrigo, Gilda y Gardel, la figura de una muerte trágica está presente en el santuario. Sin embargo, éste último tiene elementos que lo hacen único: por un lado el recuerdo no es individual sino colectivo, por el otro el grupo Callejeros intenta seguir tocando y haciendo apariciones públicas.

En la articulación escénica del santuario, puede verse una pequeña capilla en suelo de las que comúnmente usa para albergar a los santos como San Cayetano u otras imágenes; pero en este caso con la foto de uno de los fallecidos. También, hay estampada en una de las esquinas de la parte central del santuario una foto de la madre Teresa de Calcutta, en un campamento de población africana que no podemos puntualizar, con un mensaje bien claro: Justicia. En este punto, el sincretismo es una expresión profana que se une a la sacralización de los muertos como matriz sagrada. 
La evidencia testimonial que prueba que existe un vínculo entre Cromañón y la Iglesia Católica, como afirmaba Delgado, se resume a las palabras del Cardenal Bergoglio:

"Buenos Aires, trabaja hace negocios, busca rosca pero no ha llorado aún lo suficiente. Ciudad distraída, dispersa, egoísta, casquivana, superficial... Que no se nos endurezca el corazón. Buenos Aires no se ha hecho cargo de sus múltiples tragedias, tiene que llorar y ser purificada por las lágrimas" (Elustuondo, 2005).

\section{La conmemoración (los rituales)}

Las conmemoraciones y los actos religiosos tienen una función bien definida; como expresión ritual transfieren, legitiman y regulan el poder dentro de la estructura social, aseguran la continuidad de la tradición y mantienen la cohesión del grupo. (Malinoswki, 1994: 37). En la muerte, el ceremonial cumple las mismas funciones que la religión in facto esse. Afirma las creencias en una vida trascendental, fija un lugar de culto, y comunica a todos los miembros del grupo a fin de evitar su desintegración natural producidas por el miedo y la desmoralización que trae consigo la presencia de la muerte. (I bíd.: 54)

Victor Turner (1999: 65) entiende por ritual a "una conducta formal prescrita en ocasiones no dominadas por la rutina tecnológica, y relacionada con la creencia en seres o fuerzas místicas. El símbolo es la más pequeña unidad del ritual que todavía conserva las propiedades especificas de la conducta ritual".

En el santuario se celebran una misa católica todos los jueves y otra los días Domingos a las 18:00 horas, al igual que las misas celebradas en la Catedral de Buenos Aires los dos primeros Domingos del mes. Según diversas observaciones realizadas en el lugar, la misa no escapa a los rituales que comúnmente pueden observarse en una misa católica. Sin embargo, es extremadamente llamativa la poca cantidad de padres o amigos que participan en ella.

Según entrevistas sostenidas con Esteban, el policía que se desempeña como custodia del lugar, a la misma no asisten más que cinco o seis personas.

Esteban ratifica estas observaciones al afirmar que dentro del grupo de padres las opiniones están muy divididas y que posiblemente sea una causal de que muy pocos se ocupen de visitar asiduamente el santuario como en el caso de las misas que se hacen en honor a los fallecidos. Para él, el santuario parece ser una farsa, una pantalla para que operen grupos políticos. Su testimonio es elocuente al respecto "Cuando hay una marcha o algo en la Capital por Cromañón, asisten muchos cientos de padres y personas, pero acá al santuario no, no vienen más de tres personas, mira recién hablaba con una pareja de chilenos que vinieron a Buenos Aires a pasear. El santuario es un lugar de paseo más que un lugar de memoria". (Comentarios personales de Esteban).

El número 30 simboliza para todos los involucrados una de las fechas conmemorativas de lo sucedido. Todos los 30 de cada mes, se organizan eventos y marchas en alusión a la tragedia. Sin embargo, aquí hay que marcar una disociación entre lo que se puede considerar un ritual católico formal tal como una misa, y un ritual concerniente a un culto popular, como puede ser una vigilia o una marcha. 
Según comentarios de diversos informantes claves, el mismo santuario se encuentra geográficamente dividido en dos, aquella porción cedida por el Ferrocarril donde todos los jueves y domingos se lleva a cabo una misa, y aquella que corta el paso de la calle Bartolomé Mitre. Los diferentes grupos y asociaciones que se han formado reivindican ciertas partes del santuario pero desdeñan de otras.

Es el caso de Carlos quien refiriéndose a la imagen de la Virgen María sosteniendo a Jesús exclamó "eso no es el santuario de Cromañón, ahí no pasó nada los cuerpos estuvieron acá apilados en la calle Mitre, eso discúlpame la expresión es una reverenda bosta con esa imagen de mierda que está en el fondo". Nos comentó demás, que las vigilias que comenzaron en Marzo de 2005, ya no se practican más por la oposición de un grupo de padres que enérgicamente intentó expulsarlos del lugar, los mismos nos indicó que asisten a la misa católica y revindica la parte central del santuario. Como Carlos parte de los sobrevivientes no creen en Dios, pero si consideran que los fallecidos los protegen y los cuidan "desde arriba".

En determinado momento y por cuestiones ajenas a este estudio, un grupo de sobrevivientes se dividió del grupo de padres. Ese conflicto interno continúa operando y no permite que los elementos religiosos puedan articularse en un todo coherente. Algunos visitantes nos manifestaron percibir una diferencia visual bien clara entre las partes del santuario, una muy cerca de parecerse a un cementerio, la otra a una manifestación de devoción popular.

Sin embargo, en ambas existen tres elementos que no sólo representan y simbolizan a Cromañón, sino que además son visiblemente observables en cuanta manifestación o conmemoración al hecho se refiera. ${ }^{4}$ Las zapatillas de tela, que simbolizan el Rock, el nombre y apellido de los 194 fallecidos y carteles con las fotos de las víctimas. Sin ir más lejos, Carlos armó su propio santuario en su habitación manteniendo y cuidando estos tres elementos.

El fenómeno Cromañón persigue una doble dinámica, por un lado divide a los grupos ubicándolos en sentidos enfrentados con diferentes responsables, rituales, intereses y reivindicaciones territoriales. Pero por el otro, también es evidente que ciertos ritos y conmemoraciones comunes acercan las posiciones (como afirmaba Malinoswki, tienden a cohesionar al grupo).

Algunos entrevistados, aún cuando aceptaron estar divididos "por diferencias de opinión" afirmaban y recalcaban el surgimiento de una nueva estructura que los ha hermanado a todos los padres de los sobrevivientes, de las víctimas, sobrevivientes y amigos de las víctimas, La familia Cromañón. Uno de los entrevistados, Esteban de 51 años, padre de uno de los fallecidos nos decía "puede haber diferencia de pensamiento, pero estamos todos unidos y nos conocemos. Al revés, lo que hizo la desgracia ésta fue crear una nueva familia, la familia de Cromañón"

\section{Los promeseros}

Un "promesero" es individuo que se estrecha con el ser sagrado mediante una relación de obligaciones y responsabilidades a través de un prolongado período de tiempo. Al momento, en que termina la obligación cuando se cumple la promesa, se vuelve a reanudar la relación mediante otra petición. 
Eloísa Martín sostiene (2004c) “el promesero crea un lazo más fuerte y más duradero con el santo, que implica, inclusiva, casi la obligación de hace prometeros a otros y que no se rompe en toda la vida." En muchos casos, existe un fuerte condicionamiento de la tradición familiar. Por ejemplo, algunos de los "promeseros" que siguen a Gilda, heredan esa práctica de su Corrientes natal y de la devoción al gauchito Gil. El don de influir sobre la vida de los demás, sea a través de la música o mediante otros atributos, se manifiesta anterior a la muerte, y ésta apenas lo confirma y lo consolida cuando es violenta o trágica. (Martín, 2004: 112).

Pero no siempre dentro de una misma estructura se manifiesta una presencia sagrada. El caso Gilda, nos ayuda a comprender como muchas veces se dan dentro del mismo fenómeno, dos tendencias que entran en tensión; el caso de los "club de Fans" y los "devotos", mientras para los primeros Gilda no representa ni se vincula con ningún tipo de religiosidad, para el segundo grupo la cantante tiene atribuciones sagradas y ha producido una cantidad determinada de milagros que llevan a considerarla santa. Esa misma tensión tiene un origen bien marcado en la tradición cultural.

¿Qué prometen y que exigen los devotos del santuario de Cromañón?

Hemos realizado, ocho entrevistas en profundidad con diversas personas que de una u otra manera están más o menos vinculados al santuario. La tendencia fue que ninguno de ellos hasta al momento había hecho promesa alguna, con la excepción de hacer justicia en memoria de las víctimas.

Solamente Diego de 34 años, quien se desempeña como cuidador cada vez que puede, dice necesitar un poco más de tiempo para "hablar con ellos"; un tiempo justo para que él se presente y ellos lo acepten. Como él lo ha manifestado "todavía estamos hablando para que de a poquito ellos me conozcan y yo los conozca a ellos. Mucha gente se acerca y me dice que los oye, ellos están ahí se pueden sentir en espíritu". Al momento, tampoco hemos podido observar manifestaciones o testimonios que no hablen de milagros.

Por otro lado, la mayoría de los consultados coincide en llamar al lugar Santuario debido a que fue el primer lugar donde cayeron y se depositaron los primero cadáveres. Al momento de precisar bajo que nombre bautizarían nuevamente al barrio de Once, dicen "Cromañón" o "los pibes de Cromañón".

Si bien las historias de milagros son un rasgo común en todas las religiones, particularmente el cristianismo tiene una presencia muy marcada de ellos. Comparativamente, el nuevo testamento posee más milagros que el viejo y así lo entendían los religiosos medievales. (Le Goff, 1999: 14)

A diferencia de otras manifestaciones populares, no se le ha atribuido aún ningún tipo de hecho milagroso al santuario. Según los testimonios de ciertos informantes claves, se estiman que sólo hay unos 40 o 50 padres y unos 2.000 sobrevivientes y amigos de los sobrevivientes que se encuentran ligados directa 0 indirectamente a Cromañón. Aunque existen excepciones, la mayoría de sobrevivientes son seguidores de un movimiento bastante particular como lo es el rock, por ende demuestran una distancia mucho mayor con lo religioso en comparación con el grupo de padres. Esto 
sumado al hecho de ser un santuario urbano, y estar compuesto por un número elevado de víctimas, podría explicar el motivo por el cual no se han presenciado todavía testimonios de milagros.

También es llamativo que todos aquellos que reivindican la justicia como objetivo dicen estar lejos de llegar a cumplirlo.

\section{Discusión Final}

El santuario de Cromañón, se comenzó a construir a dos días de sucedida la tragedia. En un acto espontáneo en donde familiares, amigos de las víctimas, sobrevivientes y vecinos del lugar fueron dejando objetos personales y religiosos para honrar la memoria de las víctimas. Desde sus orígenes hasta la imagen que tiene hoy día, el santuario tuvo varias caras. Incluso el Ferrocarril Sarmiento donó parte de su predio para que los familiares pudieran construir un lugar donde recordar a sus seres queridos.

En cuanto a los elementos religiosos, la evidencia presentada permite afirmar que podemos considerar a Cromañón como un "Santuario urbano" en el cual se pueden observar elementos de religiosidad popular tales como una acentuada sacralización de los muertos, expresados en la figura de los ángeles y los astros como las estrellas o el sol; un sincretismo que entrelaza religión católica, fútbol y grupos de rock and roll en un mismo escenario visual; una idea de conflicto o lucha frente a un poder político y económico "plagado de corrupción", lucha que además es vinculada a la memoria de hechos que los participantes consideran similares tales como el atentado a la Amia o la muerte del periodista José Luís Cabezas; y finalmente fechas de conmemoración y rituales bien definidos, generalmente en alusión al día en que se desató la tragedia.

No obstante, a diferencia del resto de los movimientos de religiosidad popular, Cromañón tiene particularidades propias. Por un lado, carece de promeseros y devotos, por el otro tampoco se han evidenciado testimonios que hablen de hechos milagrosos. Una cantidad considerable de testimonios nos llevan a considerar la posibilidad que esto se deba al tipo de perfiles que tienen los seguidores del rock, diferente a otros perfiles culturales como pueden presentar los fieles de San Cayetano. Por otro lado, (también) cabe señalar que al tratarse de una cohorte de carácter netamente urbana la religiosidad no se manifieste a través de milagros o promesas sino que asume otras formas.

Es importante recalcar que existe una marcada tensión interna entre ciertos actores, cuyas diferencias se evidencian principalmente en los objetivos que persiguen los propios grupos. Para algunos su objetivo es intentar que I barra no vuelva a la arena política, para otros que Chaban continúe detenido y para otros que el grupo Callejeros no vuelva a tocar en público, según dicen "nunca más".

Esas diferencias, se acrecientan y llevan a establecer un lugar de pertenencia territorial diferenciado del otro significante. Por ese motivo, ciertos grupos reivindican la parte del santuario ubicada sobre la calle Bme. Mitre mientras que otros consideran como verdadero santuario al predio que les ha cedido el Ferrocarril Sarmiento. El acto espontáneo que dio nacimiento al santuario, ha sido institucionalizado y alrededor de él se han formado grupos que aunque conserven ciertas similitudes, están sujetos a 
diferentes espacios territoriales, normas, mitos de origen, rituales y a una estructura de jerarquías que algunas veces coexisten evitándose pero en otras entran en conflicto.

En el caso del Gauchito Gil, en la Provincia de Corrientes, las diferencias socioculturales se entremezclan en la devoción por este personaje, donde se comparten significaciones comunes a través de un proceso comunicativo. Nos comunicamos gracias a que compartimos ciertos significados y símbolos. Surgen, en estos contextos elementos comunes a todos los actores tales como promeseros, viajantes, devotos y turistas que los conforma como grupo homogéneo ante la mirada del observador. (Parras, 2004).

Sin embargo, la comunicación no implica una cuestión de compatibilidad lingüística exclusivamente; si nos detenemos por un momento en la fenomenología de Keen (1982) encontramos que aún compartiendo el mismo significado, hablando el mismo lenguaje, existen en la comunicación aspectos que nos impiden comprender el lugar del otro en el proceso y por tanto no entender su discurso.

Tal como afirmaba Malinowski y Berger, la muerte tiene la particularidad de disgregarnos y separarnos. En el dolor, los deudos sienten la necesidad casi inevitable de rememorar a sus muertos. Los monumentos y los santuarios tienen dos funciones fundamentales: evitar que el hecho vuelva a repetirse sobre todo cuando éste está sujeto a las fuerzas invisibles del azar y lograr la cohesión grupal. Para poder controlar el azar y garantizar el orden se deben ofrecer a los dioses ciertos sacrificios, "los chivos expiatorios" son parte de esa ofrenda, sobre la cual el grupo establece la seguridad, frente al caos que representa la inevitable presencia de la muerte. (Berger, 1971: 69)

Cabe mencionar también que la aparición de un espacio sagrado donde recordar la memoria de las víctimas de Cromañón parece ser un fenómeno común arraigado en Latinoamérica, y que encuentra su causa en la herencia cultural hispánica e indígena. Empero, aun cuando esta hipótesis parece ser ilustrativa, caben ciertas dudas. ¿Existen elementos de religiosidad o espiritualidad popular en tragedias similares?, ¿los atentados a la mutual judía en Buenos Aires o al World Trade Center en Nueva York siguen dinámicas comparables con Cromañón?, ¿Por qué? RM

\section{Bibliografía}

CAROZZI, M. 2005. "Revisando la Difunta Correa: nuevas perspectivas en el estudio de las canonizaciones populares en el Cono Sur de América. Revista de Investigaciones Folclóricas. Vol 20. Páginas. 13-21.

. 2004. "Rituales en el horario Central: sacralizando a Carlos Gardel en los hōmenajes televisivos". Ciencias Sociales y Religión. Año 6, Número 6. Páginas 11-29.

2003. "Carlos Gardel, el patrimonio que sonríe". Horizontes Antropológicos edición número 20. Páginas 59-82.

DE COULANGES, F. 2005. La Ciudad Antigua. Buenos Aires: Editorial Edaf. 
DELGADO, M. 1993. "La religiosidad popular: en torno a un falso problema". Revista Digital Gazeta de Antropología. Universidad de Barcelona. Número 10. Disponible en www.ugr.es.

ELUSTUONDO, G. 2005. "Buenos Aires tiene que llorar y ser purificada por las lágrimas", 31-12-2005. Publicado en Clarín disponible en www.clarin.com

FRIGERIO, A. 2000. “¿No será una secta?, imágenes de problemas sociales en programas televisivos de ficción". Cuadernos de Antropología. CONICET, Universidad Católica Argentina. Número 11.

FORNI, F. 1986. "Reflexión Sociológica sobre el tema de La Religiosidad Popular". Sociedad y Religión 3. Páginas 4-24.

KEEN, E. 1982. A Primer in Phenomenological Psychology. Bucknell University. Univesity Press Of. America. Lewisburg.

LE GOFF, J. 1999. Lo Maravilloso y lo Cotidiano en el Occidente Medieval. Buenos Aires: Altaya.

MARTíN, E. 2003. Religiosidad Popular: revisando un concepto problemático a partir de la bibliografía argentina. Estudios sobre Religión. Museu Nacional UFRJ . Universidad Católica Argentina. Buenos Aires.

. 2004. "No me arrepiento de este Amor. Fans y devotos de Gilda, una cantante argentina". Ciencias Sociales y Religión. Año 6 - Número 6. Páginas 101-115. Universidad Federal de Rio de Janeiro.

MALINOWSKI, B. 1993. Magia, Ciencia y Religión. Buenos Aires: Planeta Agostini.

MORENO, M. 2005. “Cromañón se sigue buscando un culpable absoluto". 2812-2005. Artículo publicado en Clarín. Disponible en www.clarin.com

PARRAS, E. 2004. "Prácticas comunicacionales vinculadas a la religiosidad popular. Devoción al Gaucho Gil." Cátedra de Investigación en Comunicación Social. Universidad Nacional del Nordeste. Comunicaciones Científicas y Tecnológicas.

TURNER, V. 1999. La Selva de Los Símbolos. Buenos Aires: Siglo XXI.

SEMÁN, P. 2001. "Cosmología, Holista y Relacional: una corriente de la religiosidad popular contemporánea". Ciencias Sociales y Religión 3. Páginas 45-74.

SONEIRA, E. (et. Al). 1996. Sociología de la Religión. Buenos Aires: Docencia.

\section{Notas}

${ }^{1}$ Marcelo es ex sobreviviente de la tragedia sucedida en Cromañón el 30 de Diciembre de 2004. 
${ }^{3}$ Se conoce a este cementerio, también bajo el nombre cementerio de La Chacarita.

${ }^{4}$ De los 194 fallecidos originalmente, tenemos testimonio que nos hablan de más fallecidos. Muchos de ellos, por ejemplo fueron trasladados a los hospitales del interior del país, de sus pueblos o ciudades de origen y fallecieron allí. Esas muertes, según nos comentaron no fueron contabilizadas como generadas por la tragedia de Cromañón. Por ello, existen en ciudades como Merlo y otras, pequeños "santuarios personales" que repiten y reproducen ciertas pautas y símbolos del santuario ubicado en Plaza Miserere. 